\title{
Management of Total Hip Replacement (THR) Luxation with Triple Pelvic Osteotomy (TPO)
}

\author{
Isobel C. Monotti ${ }^{1}$ (BVSc, MANZCVS) \\ Stewart D. Ryan ${ }^{1}$ (BVSc, MS, MANZCVS, DACVS) \\ Chris A. Preston ${ }^{2}$ (BVSc, DACVS, FANZCVS)
}

${ }^{1}$ TRACTS, U-Vet Veterinary Teaching Hospital, Faculty of Veterinary and Agricultural Sciences, The University of Melbourne, Melbourne, Australia

${ }^{2}$ Pet Emergency and Specialist Centre (PESC), Melbourne, Australia

There was no proprietary interest or funding provided for this project.

Presented at: Veterinary Orthopaedics Society Conference, Snowbird, Utah, March 17, 2017

\section{Corresponding author:}

Isobel C. Monotti

University of Melbourne Veterinary Teaching Hospital

250 Princes Hwy, Werribee, Victoria, Australia 3030

monotti.i@unimelb.edu.au

This is the author manuscript accepted for publication and has undergone full peer review but has not been through the copyediting, typesetting, pagination and proofreading process, which may lead to differences between this version and the Version of Record. Please cite this article as doi: 10.1111/vsu.12949

This article is protected by copyright. All rights reserved. 


\section{Abstract:}

OBJECTIVE: To report the outcome of dogs treated with triple pelvic osteotomy (TPO) for dorsal luxation after total hip replacement (THR).

STUDY DESIGN: Retrospective clinical case series.

ANIMALS: 17 Client-owned animals.

METHODS: Medical records were searched at a single institution for dogs treated with TPO for dorsal THR luxation. The angle of lateral opening (ALO), version angle (VA) and inclination angle (IA) were measured from radiographs after THR and TPO, and corrected for pelvic rotation. A paired t-test was performed to compare cup orientation after THR and TPO. Functional outcome was assessed at follow-up examination and during telephone interviews.

RESULTS: Eighteen TPOs were performed in 17 dogs, and radiographs were available for 15 cases. Open and/or closed hip reduction with additional stabilisation was attempted unsuccessfully in six dogs prior to TPO. TPO reduced the ALO by a mean of $23.0+/-10.9^{\circ}$ $(\mathrm{p} \leq 0.0005)$, increased VA by $9.0+/-4.9^{\circ}(\mathrm{p} \leq 0.0005)$ and IA by $2.9+/-5.8^{\circ}(\mathrm{p}=0.126)$. An excellent or good outcome was achieved in 12 dogs. Ventral luxation occurred in 3 dogs, and dorsal luxation occurred in 1 dog after TPO. TPO excessively reduced ALO in 2 dogs with ventral luxation.

This article is protected by copyright. All rights reserved. 
CONCLUSIONS: TPO with cup retention is a viable alternative to cup revision for treatment of dorsal luxation of cemented and cementless THRs. TPO significantly reduces ALO and increases VA. Careful patient selection is recommended, as excessive ventroversion can lead to ventral luxation.

CLINICAL SIGNIFICANCE: TPO offers a revision option that preserves the implant-bone interface and significantly reduces ALO. This technique may be appropriate in dogs with high ALO, luxoid hips and prior failed revision attempts.

This article is protected by copyright. All rights reserved. 
Management of Dorsal THR Luxation with TPO

This article is protected by copyright. All rights reserved. 


\section{Introduction}

Total Hip Replacement (THR) is a well-established salvage procedure to treat a variety of disabling coxofemoral injuries and developmental conditions. ${ }^{1,2}$ Excellent outcomes have been reported after THR, with standing weight distribution normalising within three months of surgery., ${ }^{3,4}$ Dorsal hip luxation is the most common, early post-operative complication, reported in $1.1-12 \%$ of cases, with $92 \%$ of these luxations occurring within the first 9 weeks after surgery. $^{2,5-9}$ Patient-related risk factors for THR luxation include severe pre-operative coxofemoral laxity, poor joint capsule strength or integrity, low soft tissue tension, as well as periarticular osteophytes and fibrous tissue restricting normal range of motion.,10 Surgeonrelated risk factors for luxation include incorrect patient positioning and inappropriate implant selection and orientation. ${ }^{2,6}$ The spatial orientation of the acetabular prosthesis is an important risk factor for impingement and luxation. Placement of the cup with an angle of lateral opening (ALO) of $35-45^{\circ}$, an inclination angle of $10^{\circ}$ and mild to moderate retroversion of $15-25^{\circ}$ has been recommended. ${ }^{11,12}$ Whereas the rates of craniodorsal luxation increase eight-fold when the ALO exceeds $60^{\circ}{ }^{6}$ version and inclination angles are considered poor predictors for luxation. ${ }^{7}$

THR luxation may be managed by re-positioning or replacing the acetabular cup, increasing femoral head size or femoral neck length, placing iliofemoral sutures, using dual mobility cups or increasing capture of the femoral head with a Triple Pelvic Osteotomy (TPO). ${ }^{6,10,13}$ The success of these procedures in preventing subsequent luxation is rarely reported, most research focusing on risk factors for initial luxation. ${ }^{6,7,14}$ TPO resulted in a successful outcome in $80 \%$ of 
dogs with traumatic coxofemoral luxation in two case series of four and 19 adult dogs. ${ }^{15-17}$ The reported advantages of TPO for traumatic coxofemoral luxation include reduced joint capsule stress and increased Norberg angle. ${ }^{17}$ TPO has only been reported for revision of THR luxation in two cases: an amputee and a giant breed dog with excessive ALO post-THR. ${ }^{10,18}$ The outcome was excellent for the amputee but the giant breed dog luxated ventrally. ${ }^{10,18}$ The main benefit of TPO over cup revision consists of the preservation of the bone-implant interface.

The objectives of our manuscript were to describe the technique to revise dorsal THR luxation with a TPO, determine resulting changes in the radiographic alignment of the coxofemoral joint, and report long-term clinical outcomes. We hypothesised that TPO would successfully treat dorsal THR luxation and results in good long-term outcomes. Based on results of TPO in juvenile dogs with hip dysplasia and traumatic hip luxations, we hypothesised that the ALO would be reduced after TPO, whereas changes in VA and IA would not be clinically significant. 


\section{Materials and Methods:}

Medical records from a single institution were searched for all dogs implanted with a modular cemented (CFX or NGD) or cementless (BFX) THR (Biomedtrix Inc., Whippany, NJ; New Generation Devices, Glen Rock, NJ) between January 2007 and January 2017. Cases were included if a TPO was performed to treat dorsal THR luxation. Complete medical records, including revisit examinations were required for inclusion.

\section{Surgical Technique:}

All procedures were performed by the same surgeon (CAP). Dogs were pre-medicated and anaesthetised with a standardised protocol including pre- and post-operative opiate analgesia and post-operative non-steroidal anti-inflammatory medications. Regional anaesthesia was achieved with epidural injection of Morphine $(0.2 \mathrm{mg} / \mathrm{kg})$ and Bupivacaine $0.5 \%(0.1 \mathrm{mg} / \mathrm{kg})$. Perioperative antibiotics (Cephazolin, 22mg/kg IV) were administered at induction and then every 90 minutes throughout the procedure. The dog was placed in lateral recumbency and the affected limb was free-draped. An impervious stockinette (Cardinal Health Inc. Dublin, Ohio) was placed over the leg and stitched into the dermis of the surgical incision. A craniodorsal approach was made to the coxofemoral joint and the luxated prosthesis was inspected before open reduction of the hip. The joint was thoroughly lavaged with sterile saline and the remnants of the joint capsule were closed using a vertical mattress suture pattern with a large, absorbable monofilament suture material.

An inguinal approach was made to the pubis and a pubic ostectomy was performed with an oscillating saw. The ischium was exposed and the hamstring muscles elevated with a periosteal 
elevator. An oscillating saw was used to cut through the ischium to the obturator foramen. The deep gluteal muscle was elevated to expose the ilial shaft and an ilial osteotomy was made. The TPO was stabilised using pre-contoured, non-locking, six-hole plates with rotation angles ranging between $20^{\circ}$ and $35^{\circ}$ or a dynamic compression plate (DCP) of appropriate size, twisted in the mid-section to rotate the acetabular segment approximately $30^{\circ}-45^{\circ}$. In some cases, an orthogonal straight DCP was also placed on the ventral aspect of the ilium for additional stability. ${ }^{19}$

An interfragmentary wire was placed at the ischial osteotomy in some dogs. The hip was moved through its range of motion and checked for luxation before closure. The middle gluteal fascia was closed to the cranial aspect of the ilial wing. An iliofemoral suture of braided multifilament, large gauge Nylon or orthopaedic wire was placed in most cases using a craniodorsal acetabular anchor and a bone tunnel through the greater trochanter. The leg was held in internal rotation and abduction during closure of the joint capsule and muscles. The avulsed deep gluteal muscle was reattached to the greater trochanter through three bone tunnels before routine closure. Intravenous antibiotics were continued every six hours for 24 hours after surgery and patients were discharged with five days of Cephalexin (22mg/kg PO BID).

\section{Radiographic Interpretation:}

Dogs were included for visual examination and radiographic measurement of ALO, VA and IA if radiographs were available after THR and TPO. Pre-operative radiographs were assessed for 
coxofemoral subluxation and osteoarthritis before THR. Hips were defined as luxoid if severe hip dysplasia was manifested by non-traumatic hip luxation.

Radiographic images were imported to an image analysis program (ImageJ, National institutes of health, Bethesda, MD) and the images were calibrated using the known diameter of the prosthetic femoral head. The ALO, VA and IA were measured for each procedure. Each measurement was repeated three times and the mean of those three measurements was recorded. The measured angles were corrected for the degree of pelvic rotation using a previously described technique. $^{20}$

For cemented THR cases, the ALO was calculated using the ellipse of best-fit method (Figure 1). ${ }^{20,21}$ For uncemented THR cases, the ALO for size 24, 28 and 32mm cups was measured using a system described by Renwick et al. ${ }^{11}$ If a size 20,26 or 30mm cup was used, the ALO was estimated from the data available. ${ }^{11}$ Version and inclination angles were determined from ventrodorsal and lateral pelvic projections respectively using previously described techniques. ${ }^{21}$

\section{Complications and Clinical Outcomes Assessment:}

Intra- and post-operative complications were listed as major or minor according to previously described criteria. ${ }^{22}$ Short-term outcome was measured as the first 12 weeks after TPO and longterm outcome was defined as 12 weeks or more after TPO. Long-term, functional outcome of the operated limb was evaluated using medical records and a telephone interview of the owner. Dogs 
were classified as having an excellent, good or poor outcome based on previously reported standards. $^{22}$

\section{Statistical Analysis}

Descriptive statistics (median, range and frequency) collected from the medical records included patient age, sex, breed, reason for THR, affected limb, THR system used, time to luxation, trauma associated with luxation, the number and type of revision procedures performed prior to TPO as well as any complications, including repeat luxation. The mean and median ALO, VA and IA following THR and TPO were determined. A paired t-test was performed to compare ALO, VA and IA after THR and TPO. Statistical significance was set at $\mathrm{p} \leq 0.05$. 
Management of Dorsal THR Luxation with TPO

\section{Results:}

Over the ten-year study period, 354 THR procedures were performed in 300 dogs. Twenty-nine craniodorsal luxations were identified during the study period and 18 (62\%) of them were managed with TPO (Figure 2). Complete medical records were available for 18 TPO procedures in 17 dogs (Table 1). Eleven dogs were male and six dogs were female. Breeds represented in this study included Bernese Mountain Dogs (6), Labrador retrievers (2), Pugs (2) and one each of

This article is protected by copyright. All rights reserved. 
Labradoodle, Rottweiler, Border Terrier, Australian Terrier, German Shepherd Dog, Great Dane and Golden Retriever. During this study period, 13 THRs were performed in 11 Bernese Mountain Dogs. Six (46\%) of these luxated dorsally and all were managed with TPO.

Staged bilateral THR was performed in two dogs and all other dogs received unilateral THR. A cemented THR was performed in seven cases and a cementless THR was used in eleven cases. The mean age at the time of THR was 4.4 years (+/-3 years, range 1-12 years). The indication for THR was osteoarthritis, secondary to hip dysplasia in 16 dogs. One dog underwent THR after a failed capital physeal fracture repair and subsequent failed femoral head and neck excisional arthroplasty. One dog had a Juvenile Pubic Symphysiodesis (JPS) as a puppy, however, developed clinically significant hip laxity, necessitating a THR as an adult.

Luxation was diagnosed 30 days (median, range, 1-730 days) after THR. A traumatic event, such as a fall, transportation or poor confinement in the perioperative period preceded luxation in seven cases. The median time to traumatic luxation was 29 days (range, 5-730 days), compared to 31 days (range, 1-202 days) in dogs without trauma. Closed or open reduction techniques were attempted but failed in six dogs prior to performing TPO. Closed reduction and Ehmer sling placement was performed in two dogs, open reduction was performed in two dogs and both open and closed techniques were attempted in two dogs prior to TPO. Procedures performed during open reduction included placement of an iliofemoral suture in four dogs and femoral head exchange to increase prosthetic neck length in two dogs. Femoral stem and head exchange was performed in one dog for management of stem subsidence one month prior to luxation occurring. 
The median time between THR luxation and TPO was 6 days (range, 0 to 171 days). Additional procedures performed with TPO included placement of an iliofemoral suture in 15 dogs, an ischial interfragmentary wire in four dogs and an orthogonal, ventral ilial plate in five dogs. Femoral head exchange was performed in two dogs at the time of TPO. The acetabular cup was not exchanged or repositioned in any dogs. No intra-operative complications were reported.

\section{Radiographic Interpretation:}

Of the 18 TPO cases, 15 had radiographs from which ALO and VA could be accurately measured. IA could be accurately measured in 11 cases. Four hips were luxoid prior to THR. All ilial osteotomies healed without complication and no mechanical complications, including screw loosening or pull-out, fracture, loss of reduction or pelvic narrowing were observed.

The mean ALO post-THR was $58.6^{\circ}+/-16.6^{\circ}$ (median $54.9^{\circ}$, range $32.7^{\circ}-78.9^{\circ}$ ). Eleven of the dogs had an “open” acetabular cup after THR. Mean VA was $21.2^{\circ}+/-8.6^{\circ}$ (median $20.1^{\circ}$, range $9.6^{\circ}-36.4^{\circ}$ ) and mean IA was $28.2^{\circ}+/-7.3^{\circ}$ (median $25.2^{\circ}$, range $20.6^{\circ}-42.1^{\circ}$ ) following THR. Mean ALO post-TPO was $34.0^{\circ}+/-18.6^{\circ}$ (median $33.1^{\circ}$, range $8.3^{\circ}-65.2^{\circ}$ ). Mean VA and IA post-TPO were $30.1^{\circ}+/-10.2$ (median $28.1^{\circ}$, range $15.7^{\circ}-54.1^{\circ}$ ) and $31.8^{\circ}+/-9.1^{\circ}\left(\operatorname{median} 30.5^{\circ}\right.$, range $\left.15.8^{\circ}-48.4^{\circ}\right)$.

The median intended closure of the cup with TPO was $30^{\circ}$ (range, $20^{\circ}-45^{\circ}$ ). TPO reduced ALO by a mean of $23.0^{\circ}+/-10.9^{\circ}$ (median $20.2^{\circ}$, range $9.7^{\circ}-45.0^{\circ}, \mathrm{p} \leq 0.0005$ ) and increased mean VA 
by $9.0^{\circ}+/-4.9^{\circ}$ (median $8.4^{\circ}$, range $3.1^{\circ}$ to $20.1^{\circ}, \mathrm{p} \leq 0.0005$ ) and IA by $2.9^{\circ}+/-5.8^{\circ}$ (median $2.3^{\circ}$, range $-5.6^{\circ}$ to $\left.13.9^{\circ}, \mathrm{p}=0.126\right)$.

\section{Complications}

Minor post-operative complications included two superficial surgical site infections and one bone anchor avulsion. Major post-operative complications included deep infections in two dogs and re-luxation in four dogs. Of the four dogs that luxated, one luxated dorsally and three luxated ventrally (Figure 3). The post-TPO angles of lateral opening for dogs with ventral luxation were $8.5^{\circ}, 37.5^{\circ}$ and $10.8^{\circ}$. One ventral luxation was attributed to stem subsidence (case 11) and had a post-TPO ALO of $37.5^{\circ}$. The median time between TPO to repeat luxation was 42 days (range, 13-56 days).

\section{Clinical Outcome:}

Short-term outcome was poor for 3 of the 18 cases. One dog was euthanized 13 days after TPO due to deep infection and dorsal luxation sustained after a fall. One dog was euthanized seven weeks after TPO due to recurrent ventral luxations, despite further revision attempts. Another dog became non-ambulatory with severe, deep infection four weeks after TPO. The patient was given a guarded prognosis with recommendations for explantation, amputation or euthanasia. The other 15 cases had an unremarkable recovery from surgery.

This article is protected by copyright. All rights reserved. 
Long-term follow-up information from telephone interviews with owners or from referring veterinary records was available for 12 of the remaining 15 dogs. The median follow-up time for these 15 dogs was 686 days (range, 48-2764 days).

Nine TPO procedures performed in eight dogs had an excellent long-term outcome and normal function of the limb was achieved. Three dogs had a good outcome and three dogs had a poor outcome. Explantation was performed in one dog due to recurrent ventral luxations, 639 days after TPO. Two dogs had a poor long-term outcome without known infection or mechanical complications. 


\section{Discussion:}

This study provides evidence to support TPO with acetabular cup retention as a viable option to manageme dorsal THR luxation in adult dogs. TPO prevented recurrent dorsal luxation in 17 dogs, with excellent or good clinical outcome in 12 dogs. In this series, TPO was the preferred revision procedure in dogs with a high ALO, pre-operative luxoid hip status or failed prior attempts at open reduction. The goals of TPO were to reduce ALO to $30^{\circ}-40^{\circ}$ and preserve the implant-bone interface.

Both closed and open revision techniques have been described to manage luxated total hip replacements. Previous studies have documented the ineffectiveness of closed reduction and placement of an Ehmer sling in preventing re-luxation. ${ }^{2}$ Closed reduction was performed five times in four dogs in this study, all of which re-luxated and required surgical revision. In people, revision surgery is maintains reduction in $70-80 \%$ of cases, when a technical error is identified and corrected. ${ }^{6,23,24}$ If an underlying cause is not identified and the implant appears well positioned, revision surgery is successful in only $30-50 \%$ of cases. ${ }^{6,23,24}$ A variety of other hip stabilisation techniques were deployed during open reduction in four cases before TPO.

In some cases of cup misalignment, revision acetabular arthroplasty may be the best option. However, removal of the cemented or integrated cementless implants can be challenging or 
risky, and the orientation of the cup may not be significantly improved. In a report of eight CFX THR luxations successfully treated with acetabular cup revision, the mean ALO was reduced from $62^{\circ}$ to $52^{\circ}$ and seven dogs regained normal or near-normal function. ${ }^{6}$ In this study, TPO reduced the mean ALO from $58.6^{\circ}$ to $34.0^{\circ}$. Eighty percent of cases available for long-term follow up and (12/18) 66\% of all TPO cases had an excellent or good long-term outcome. The main advantage of a TPO consists of capturing the femoral head while preserving the acetabular implant-bone interface or cement mantle. The stability of the BFX cup initially depends on the quality and quantity of bone in the acetabulum, which could be compromised by reaming during cup revision. ${ }^{25}$ Osseointegration of cementless THR implants is expected to occur within the first six weeks after surgery, with little movement occuring after three months. ${ }^{26}$ The median time to luxation of BFX THRs in this study was 30 days, at which point osseointegration should have progressed significantly. During the study period, the ingrowth surface of the Biomedtrix acetabular cup was changed from Cobolt Chromium sintered beads to a Titanium electron beam melted (EBM) surface. The EBM surface has a higher coefficient of friction and more closely imitates cancellous bone, improving the stability of the porous-substrate interface and increasing removal torque. ${ }^{27,28}$ Improvements in implant technology and osseointegration may make cup revision of cementless THR more challenging. ${ }^{28}$

Aseptic loosening of cemented implants is reportedly more frequent after revision surgery. ${ }^{29,30}$ Particulate wear debris produced by unstable cemented implants induce inflammation, reducing bone stock and affecting the environment for long term implant stability. ${ }^{29}$ TPO may therefore be 
a good option for cup re-orientation in cemented THR. Cases were selected for TPO if the acetabular cup had an open orientation, if the native hip was luxoid or if prior open reduction procedures had failed. Nine dogs were treated with TPO due to high ALO and six of these dogs had CFX cups. A loss of up to 50\% of the dorsal acetabular rim (DAR) does not reduce BFX acetabular stability at physiologic loads. ${ }^{25,31}$ This feature reduces the chance of inserting BFX cups with high ALO as the cup can tolerate greater exposure of the dorsal surface. The CFX cup, however, relies on the DAR for adequate fixation and dispersion of forces along the acetabulum. ${ }^{25,31}$ Revision acetabular arthroplasty may not be suitable in cases with diminished DAR as further ventroversion increases exposure of the dorsal aspect of the cup. TPO is therefore advantageous in cases with reduced bone stock and cemented implants.

Performing a revision TPO reduced the mean ALO by $23.0^{\circ}$ and is therefore a good revision option when ALO is high. This is a desirable magnitude of rotation as acetabular ventroversion exceeding $20^{\circ}$ does not significantly increase femoral head coverage and could increase the risk of complications such as reduced range of motion, impingement and medial subluxation. ${ }^{32,33}$ The mean ALO following TPO was $34.0^{\circ}$, bringing the ALO within the desired range and satisfying the main goal of surgery. Seven of the nine dogs that had TPO due to high ALO had an excellent or good outcome and two had poor outcomes without post-operative complications. The magnitude of ALO closure with TPO was within $10^{\circ}$ of the expected rotation when a precontoured TPO plate was used. This difference between change in ALO and TPO plate angle is within the expected margin of error for radiographic ALO measurement. Greater variation 
between the change in ALO and the TPO plate rotation angle was seen with the twisted DCP and likely represents inaccuracy in the estimated plate angle at the time of surgery.

A TPO was performed in two dogs with pre-operative luxoid hips and adequate ALO. Preoperative soft tissue laxity and hip subluxation are reported risks for THR luxation. ${ }^{5}$ Open reduction with placement of an iliofemoral suture was performed in four dogs prior to TPO to improve soft tissue tension. However, this was ineffective in maintaining reduction of the prosthesis, indicating that further intervention was required. The goal of TPO in cases of inadequate soft tissue tension was to combat the joint's predisposition for luxation by increasing coverage of the femoral head, without disrupting osseointegration or compromising cup position in the acetabulum. An excellent outcome was achieved in one of these dogs and the other luxated ventrally.

An iliofemoral suture was placed in 15 dogs, as described to increase joint capsule tension and resist dorsal luxation in traumatic coxofemoral luxations. ${ }^{10,34-36}$ Although the iliofemoral suture alone did not prevent re-luxation in four cases, the authors recommend its application as part of a multimodal approach to a multifactorial complication. TPO was performed in five dogs with previous, failed revision attempts. These dogs did not have excessive ALO or pre-operative luxoid hips and TPO was performed due to exhaustion of other surgical options. THR luxation traumatises the periarticular soft tissues, increasing the risk of recurrent luxation with each revision procedure. ${ }^{23,37}$ TPO was performed in these cases to minimise further soft tissue damage 
and to preserve the bone-implant interface. ${ }^{29,30}$ One of these dogs had a poor outcome resulting in explantation and four dogs had an excellent or good outcome.

Infection of canine THR is reported in up to $11 \%$ of cases. ${ }^{15}$ Risk factors for infection include longer surgery time and multiple procedures. ${ }^{8,38,39}$ The reported infection rate for revision total hip and knee replacements in people is two to three times that of the primary procedure. ${ }^{39}$ Two (11\%) cases in this study developed deep infection following TPO. Although this is comparable to previously reported infection rates for primary THR, it is much higher than the infection rate (2\%) for primary THR at this institution. ${ }^{40}$ These implant infections may be due to the placement of a multifilament iliofemoral suture, multiple revision procedures prior to TPO or exposure of the prosthesis during revision. The risk of infection may make TPO a less desirable treatment option; however, the infection rate for other revision techniques is currently unknown.

All ilial osteotomies healed without post-operative complications. Screw loosening has been reported to occur in up to $70 \%$ of cases following TPO in juvenile patients. ${ }^{41,42}$ Implant loosening has been associated with loss of ventroversion and pelvic narrowing. Two additional techniques were employed in this study to prevent mechanical implant failure. A ventral DCP was placed in five dogs to increase the axial bending stiffness of the TPO ${ }^{19}$ An ischial wire was also placed in four dogs to reduce cantilever bending forces at the level of the ilial osteotomy.

Luxation recurred after TPO in four dogs, one in a dorsal direction, and three in a ventral direction. Previously identified risks for ventral luxation after THR include Saint Bernard-type 
breed, short neck extension and high ALO in other breeds, with recurrent ventral luxations associated with a poor prognosis. ${ }^{14}$ The findings of this study are similar, with two ventral luxations occurring in Bernese Mountain dogs attributed to excessive acetabular ventroversion and low ALO. Both dogs had poor outcomes due to recurrent ventral luxations, despite further revision procedures.

TPO reduced ALO and increased VA, but did not influence the IA. Although VA and IA are not reported risk factors for luxation, the combined reduction of ALO and increase in VA and IA could result in impingement and contribute to ventral luxation. The ALO was not measured prior to TPO and the rotation angle of the pre-contoured TPO plate or twist angle in the ilial DCP was determined through visual estimation at the time of surgery. Based on the results of this study, the authors do not recommend a TPO in dogs with appropriate cup orientation and recommend using only custom TPO plates to prevent inadvertent over-rotation of the hemipelvis. An alternative revision option for dogs with adequate ALO includes placement of a size $22 \mathrm{~mm}$ or 24mm femoral head. The larger head increases jumping distance, reducing the risk of reluxation. ${ }^{10}$ However, the $22 \mathrm{~mm}$ femoral head requires at least a $30 \mathrm{~mm}$ cup and only two dogs in this study could accommodate a cup of this size. The surface of the luxated femoral head is inevitably damaged through abrasion against the titanium shell of the acetabular cup, accelerating wear of the UHMWPE liner. ${ }^{43,44}$ In this study, the femoral head was replaced in only two dogs at the time of TPO. Femoral head exchange is therefore indicated in all open revision procedures to ensure expected longevity of the prosthesis. 
Limitations of this study are largely attributed to its retrospective nature. Variations in animal size and age, time between luxation and TPO and the number and type of revision attempts before TPO are noted. The placement of an iliofemoral suture in most dogs may be a confounding variable, preventing the assessment of TPO alone. The inclusion of both cemented and cementless THRs in this study implies the use of different techniques to measure ALO. The ellipse and Renwick methods for ALO measurement have a reported accuracy of $5^{\circ}-10^{\circ}$, however, their accuracy decreases with increasing IA, pelvic rotation and decreasing ALO. ${ }^{11,20,21}$ The accuracy of VA measurement is affected by declining ALO, cup size and IA. ${ }^{11}$ Therefore, the change in VA after TPO could be artefactual and confounded by the changes in ALO and should be interpreted with caution. ${ }^{21}$ Patient positioning was inconsistent between THR and TPO in some cases and could have influenced comparison of cup orientation between the two procedures. ALO and VA measurements were corrected for pelvic rotation to account for variation in patient positioning, however, radiographic calculation of pelvic rotation is only accurate to within $5^{\circ}$ and could also affect measured results. ${ }^{21}$

Multiple revision surgeries after THR luxation are undesirable due to increased morbidity, cost and client frustration. TPO offers an option to revise dorsal THR luxation, preserving the acetabular implant-bone interface and improving the capture of the femoral head by reducing ALO. Careful patient selection is required and care should be taken to ensure ALO and VA are not excessively altered, to avoid ventral luxation. 


\section{References:}

1. Gemmill TJ, Pink J, Clarke SP, et al: Total hip replacement for the treatment of atraumatic slipped femoral capital epiphysis in dogs. J Small Anim Pract 53:453-458, 2012.

2. Olmstead ML, Hohn RB, Turner TM: A five-year study of 221 total hip replacements in the dog. J Am Vet Med Assoc 183:191-194, 1983.

3. Marcellin-Little DJ, DeYoung BA, Doyens DH, et al: Canine uncemented porous-coated anatomic total hip arthroplasty: results of a long-term prospective evaluation of 50 consecutive cases. Vet Surg 28:10-20, 1999.

4. Lascelles BD, Freire M, Roe SC, et al: Evaluation of functional outcome after BFX total hip replacement using a pressure sensitive walkway. Vet Surg 39:71-77, 2010.

5. Hayes GM, Ramirez J, Langley Hobbs SJ: Does the degree of preoperative subluxation or soft tissue tension affect the incidence of postoperative luxation in dogs after total hip replacement? Vet Surg 40:6-13, 2011.

6. Dyce J, Wisner ER, Wang Q, et al: Evaluation of risk factors for luxation after total hip replacement in dogs. Veterinary Surgery 29:524-532, 2000.

This article is protected by copyright. All rights reserved. 
7. Cross AR, Newell SM, Chambers JN, et al: Acetabular component orientation as an indicator of implant luxation in cemented total hip arthroplasty. Veterinary Surgery 29:517-523, 2000.

8. Bergh MS, Gilley RS, Shofer FS, et al: Complications and radiographic findings following cemented total hip replacement: a retrospective evaluation of 97 dogs. Vet Comp Orthop Traumatol 19:172-179, 2006.

9. Massat BJ, Vasseur PB: Clinical and radiographic results of total hip arthroplasty in dogs: 96 cases (1986-1992). J Am Vet Med Assoc 205:448-454, 1994.

10. Roe SC, Sidebotham C, Marcellin-Little DJ: Acetabular cup liner and prosthetic head exchange to increase the head diameter for management of recurrent luxation of a prosthetic hip in two dogs. Vet Comp Orthop Traumatol 28:60-66, 2015.

11. Renwick A, Gemmill T, Pink J, et al: Radiographic evaluation of BFX acetabular component position in dogs. Vet Surg 40:610-620, 2011.

12. Olmstead ML: The canine cemented modular total hip prosthesis. J Am Anim Hosp Assoc 31:109-124, 1995.

13. Guillaumot P, Autefage A, Dembour T, et al: Outcome and complications after dual mobility total hip replacement: fifty cases with a minimum of six months clinical and radiographic followup. Vet Comp Orthop Traumatol 25:511-517, 2012.

14. Nelson LL, Dyce J, Shott S: Risk factors for ventral luxation in canine total hip replacement. Vet Surg 36:644-653, 2007.

15. Iwata D, Broun HC, Black AP, et al: Total hip arthroplasty outcomes assessment using functional and radiographic scores to compare canine systems. Vet Comp Orthop Traumatol 21:221$230,2008$.

16. Haburjak JJ, Lenehan TM, Harari J, et al: Treatment of Traumatic Coxofemoral Luxation with Triple Pelvic Osteotomy in 19 Dogs (1987-1999). Vet Comp Orthop Traumatol:69-77, 2001.

17. Murphy ST, Lewis DD, Kerwin SC: Traumatic Coxofemoral Luxation in Dysplastic Dogs Managed with a Triple Pelvic Osteotomy: Results in Four Dogs. Vet Comp Orthop Traumatol 10:136140, 1997.

18. Preston C, Shulz K, Vasseur P: Total Hip Arthroplasty in Nine Canine Hind Limb Amputees: A Retrospective Study. Veterinary Surgery 28:341-347, 1999.

19. Fitch RB, Hosgood G, Staatz A: Biomechanical Evaluation of Triple Pelvic Osteotomy with and without Additional Ventral Plate Stabilisation. Vet Comp Orthop Traumatol 15:145-149, 2002.

20. Cross AR, Newell SM: Definition and determination of acetabular component orientation in cemented total hip arthroplasty. Veterinary Surgery 29:507-516, 2000.

21. Dyce J, Wisner ER, Schrader SC, et al: Radiographic evaluation of acetabular component position in dogs. Veterinary Surgery 30:28-39, 2001.

22. Cook JL, Evans R, Conzemius MG, et al: Proposed definitions and criteria for reporting time frame, outcome, and complications for clinical orthopedic studies in veterinary medicine. Vet Surg 39:905-908, 2010.

23. Morrey BF: Difficult complications after hip joint replacement. Dislocation. Clin Orthop Relat Res:179-187, 1997.

24. Hedlundh U, Sanzen L, Fredin H: The prognosis and treatment of dislocated total hip arthroplasties with a 22 mm head. J Bone Joint Surg Br 79:374-378, 1997. 
25. Montgomery ML, Kim SE, Dyce J, et al: The effect of dorsal rim loss on the initial stability of the BioMedtrix cementless acetabular cup. BMC Vet Res 11:68, 2015.

26. Korani HM, Marcellin-Little DJ, Roe SC: Variability associated with assessing changes in position of a canine uncemented femoral stem prosthesis. Vet Comp Orthop Traumatol 28:409-416, 2015.

27. Liska WD, Doyle ND: Use of an Electron Beam Melting Manufactured Titanium Collared Cementless Femoral Stem to Resist Subsidence After Canine Total Hip Replacement. Vet Surg 44:883-894, 2015.

28. Ruppert DS, Harrysson OLA, Marcellin-Little DJ, et al: Osseointegration of Coarse and Fine Textured Implants Manufactured byelectron Bea, Melting and Direct Metal Laser Sintering. 3D Printing and Additive Manufacturing 4:91-97, 2017.

29. Bergh MS, Muir P, Markel MD, et al: Femoral bone adaptation to unstable long-term cemented total hip arthroplasty in dogs. Vet Surg 33:238-245, 2004.

30. Skurla CP, James SP: Assessing the dog as a model for human total hip replacement: analysis of 38 postmortem-retrieved canine cemented acetabular components. J Biomed Mater Res B Appl Biomater 73:260-270, 2005.

31. Hunter S, Dyce J, Butkus L, et al: Acetabular Cup Displacement After Polyethylene-Cement Interface Failure: A Complication of Total Hip Replacement in Seven Dogs. Vet Comp Orthop Traumatol 16:99-104, 2003.

32. Dejardin LM, Perry RL, Arnoczky SP: The effect of triple pelvic osteotomy on the articular contact area of the hip joint in dysplastic dogs: an in vitro experimental study. Vet Surg 27:194-202, 1998.

33. Tomlinson JL, Cook JL: Effects of degree of acetabular rotation after triple pelvic osteotomy on the position of the femoral head in relationship to the acetabulum. Veterinary Surgery 31:398-403, 2002.

34. Meij BP, Hazewinkel HAW, Nap RC: Results of Extra-articular stabilisation Following Open Reduction of Coxofemoral Luxation in Dogs and Cats. J Small Anim Pract 33:320-326, 1992.

35. Martini FM, Simonazzi B, Del Bue M: Extra-articular absorbable suture stabilization of coxofemoral luxation in dogs. Veterinary Surgery 30:468-475, 2001.

36. Shani J, Johnston DE, Shahar R: Stabilisation of Traumatic Coxofemoral Luxation with an Extracapsular Stabilisation from the Greater Trochanter to the Origin of the Rectus Femoris. Vet Comp Orthop Traumatol 17:12-16, 2004.

37. Su EP, Pellicci PM: The role of constrained liners in total hip arthroplasty. Clin Orthop Relat Res 420:122-129, 2004.

38. Ireifej S, Marino DJ, Loughin CA, et al: Risk factors and clinical relevance of positive intraoperative bacterial cultures in dogs with total hip replacement. Vet Surg 41:63-68, 2012.

39. Voigt J, Mosier M, Darouiche R: Antibiotics and antiseptics for preventing infection in people receiving revision total hip and knee prostheses: a systematic review of randomized controlled trials. BMC Infect Dis 16:749, 2016.

40. Kidd SW, Preston CA, Moore GE: Complications of porous-coated press-fit cementless total hip replacement in dogs. Vet Comp Orthop Traumatol 29:402-408, 2016. 
41. Hosgood G, Lewis DD: Retrospective Evaluation of Fixation Complications of 49 Pelvic Ostoeomties in 36 Dogs. J Small Anim Pract 34:123-130, 1993.

42. Remedios AM, Fries CL: Implant Complications in 20 Triple Pelvic Osteotomies. Vet Comp Orthop Traumatol:202-207, 1993.

43. Lapaj L, Wendland J, Markuszewski J, et al: Retrieval analysis of titnium nitride (TiN) coated prosthetic femoral heads articualting with polyethylene. Journal of the Mechanical behaviour of Biomedical Meterials 55:127-139, 2016.

44. Evangelista GT, Fulkerson E, Kummer F, et al: Surface damage to an Oxinium femoral head prosthesis after dislocation. J Bone Joint Surg 89-B:535-537, 2007. 


\section{Figure Legend:}

Figure 1: Examples of the ellipse (A) and Renwick (B) methods for determining ALO in cemented and cementless THR systems on a ventrodorsal pelvic radiograph. For the ellipse method, ALO is calculated using the equation ALO $=\cos ^{-1}(\mathrm{a} / \mathrm{b}) .{ }^{21}$ Using the Renwick method, the distance between the centre of the femoral head and the truncated surface of the cup is measured and that distance correlates to a known ALO for the cup size. ${ }^{11}$

Figure 2: Example of a successful revision TPO. The pre-TPO ALO in this dog was $38.2^{\circ}$. A TPO was performed (pTPO35 ${ }^{\circ}$ plate) after failed open reduction with placement of an iliofemoral suture. The resultant ALO was $12.2^{\circ}$. A medial calcar fissure developed at the index surgery and stem exchange (BFX to NGD) was performed due to subsidence 5 weeks before luxation occurred. Periosteal new bone is seen due to fracture healing. The stem remained stable and the patient had a good outcome with TPO.

Figure 3: Ventral luxation after revision TPO surgery. The post-TPO ALO was $8.5^{\circ}$. 
Table 1: Summary data.

Abbreviations: IFS, iliofemoral suture; pTPO, pre-contoured TPO plate; tDCP, twisted dynamic compression plate.

\begin{tabular}{|c|c|c|c|c|c|c|c|c|c|c|c|}
\hline Case & Signalment & $\begin{array}{l}\text { THR } \\
\text { system }\end{array}$ & $\begin{array}{l}\text { Time to } \\
\text { luxation } \\
\text { (days) }\end{array}$ & $\begin{array}{l}\text { THR ALO } \\
\text { (TPO ALO) } \\
\text { (degrees) }\end{array}$ & $\begin{array}{l}\text { THR VA } \\
\text { (TPO VA) } \\
\text { (degrees) }\end{array}$ & $\begin{array}{l}\text { THR IA } \\
\text { (TPO IA) } \\
\text { (degrees) }\end{array}$ & TPO plate & $\begin{array}{l}\text { Indication } \\
\text { for TPO }\end{array}$ & $\begin{array}{l}\text { Adjunctive } \\
\text { procedures } \\
\text { at TPO }\end{array}$ & $\begin{array}{l}\text { Post-TPO } \\
\text { complication }\end{array}$ & Outcome \\
\hline 1 & $\begin{array}{l}8 \text { yr., F, } \\
\text { Great Dane }\end{array}$ & CFX & 14 & NA & NA & NA & pTPO $25^{\circ}$ & Unknown & IFS & $\begin{array}{l}\text { Deep } \\
\text { infection, } \\
\text { dorsal } \\
\text { luxation }\end{array}$ & $\begin{array}{l}\text { Poor, } \\
\text { euthanasia }\end{array}$ \\
\hline 2 & $\begin{array}{l}1 \text { yr., F, } \\
\text { Bernese } \\
\text { Mountain } \\
\text { Dog (BMD) }\end{array}$ & BFX & 14 & NA (8.5) & NA (27.5) & NA (38.4) & pTPO $20^{\circ}$ & $\begin{array}{l}\text { Failed } \\
\text { revision }\end{array}$ & $\begin{array}{l}\text { Head } \\
\text { exchange }\end{array}$ & $\begin{array}{l}\text { Tissue anchor } \\
\text { avulsion, } \\
\text { Ventral } \\
\text { luxation }\end{array}$ & $\begin{array}{l}\text { Poor, } \\
\text { explant }\end{array}$ \\
\hline 3 & $\begin{array}{l}\text { 1.5yr, M, } \\
\text { Rottweiler }\end{array}$ & BFX & 202 & $54(44.3)$ & $22.3(28.1)$ & NA (46.6) & pTPO & $\begin{array}{l}\text { Failed } \\
\text { revision }\end{array}$ & $\begin{array}{l}\text { Ischial wire, } \\
\text { IFS }\end{array}$ & None & Excellent \\
\hline 4 & $\begin{array}{l}\text { 4yr, M, } \\
\text { Golden } \\
\text { Retriever }\end{array}$ & CFX & 7 & NA & NA & NA & pTPO $25^{\circ}$ & Unknown & IFS & $\begin{array}{l}\text { Deep } \\
\text { infection }\end{array}$ & Poor \\
\hline 5 & 5yr, F, Pug & BFX & 45 & $42.2(22.1)$ & $9.6(15.7)$ & $21.4(15.8)$ & $\mathrm{tDCP} \approx 40^{\circ}$ & $\begin{array}{l}\text { Luxoid } \\
\text { hip }\end{array}$ & IFS & None & Excellent \\
\hline 6 & $\begin{array}{l}\text { 2yr, M, } \\
\text { BMD }\end{array}$ & $\begin{array}{l}\text { BFX } \\
\text { with } \\
\text { NGD } \\
\text { stem }\end{array}$ & 102 & 38.2 (12.2) & $16.3(19.4)$ & $31.8(30.5)$ & pTPO $35^{\circ}$ & $\begin{array}{l}\text { Failed } \\
\text { revision }\end{array}$ & $\begin{array}{l}\text { Ischial wire, } \\
\text { head } \\
\text { exchange, } \\
\text { IFS }\end{array}$ & None & Good \\
\hline 7 & $\begin{array}{l}5 \text { yr., M, } \\
\text { Border } \\
\text { Terrier }\end{array}$ & CFX & 61 & $78.9(65.2)$ & $34.0(54.1)$ & NA & tDCP & High ALO & IFS & None & Poor \\
\hline 8 & $\begin{array}{l}\text { 4yr, F, } \\
\text { Labrador }\end{array}$ & BFX & 29 & $51.4(34.2)$ & $28.5(37.3)$ & $28.9(37.0)$ & pTPO 25 & $\begin{array}{l}\text { Failed } \\
\text { revision }\end{array}$ & $\begin{array}{l}\text { Ischial wire, } \\
\text { IFS }\end{array}$ & None & Excellent \\
\hline 9 & $\begin{array}{l}\text { 4yr, M, } \\
\text { Labradoodle }\end{array}$ & CFX & 730 & $75.0(42.5)$ & NA & $39.3(42.2)$ & $\mathrm{tDCP} \approx 45^{\circ}$ & High ALO & IFS & None & Poor \\
\hline 10 & 8yr, M, Pug & CFX & 78 & $72.4(62.5)$ & $36.4(45.2)$ & $42.1(48.4)$ & $\mathrm{tDCP} \approx 30^{\circ}$ & High ALO & Ischial wire & None & Excellent \\
\hline 11 & $\begin{array}{l}1 \text { yr., } \mathrm{M} \text {, } \\
\text { German }\end{array}$ & BFX & 1 & 78.3 (37.5) & $13.1(24.9)$ & $25.8(39.7)$ & pTPO $35^{\circ}$ & High ALO & None & $\begin{array}{l}\text { Ventral } \\
\text { luxation due }\end{array}$ & Good \\
\hline
\end{tabular}


Management of Dorsal THR Luxation with TPO

\begin{tabular}{|c|c|c|c|c|c|c|c|c|c|c|c|}
\hline & Shepherd & & & & & & & & & to subsidence & \\
\hline 12 & $\begin{array}{l}12 \text { yr., M, } \\
\text { Labrador }\end{array}$ & CFX & 16 & $76.1(55.7)$ & 20.1(37) & $20.6(28.5)$ & pTPO $30^{\circ}$ & High ALO & IFS & $\begin{array}{l}\text { Superficial } \\
\text { infection }\end{array}$ & Excellent \\
\hline 13 & $\begin{array}{l}3 \text { yr., M, } \\
\text { BMD }\end{array}$ & BFX & 143 & $32.7(8.3)$ & $15.6(21.8)$ & $24.5(21.6)$ & pTPO $30^{\circ}$ & $\begin{array}{l}\text { Failed } \\
\text { revision }\end{array}$ & $\begin{array}{l}\text { head } \\
\text { exchange, } \\
\text { IFS }\end{array}$ & None & Good \\
\hline 14 & $\begin{array}{l}1 \text { yr., F, } \\
\text { BMD }\end{array}$ & BFX & 22 & 41.1 (31.9) & $22.7(29.5)$ & NA (32.8) & pTPO & $\begin{array}{l}\text { Failed } \\
\text { revision }\end{array}$ & IFS & None & Excellent \\
\hline 15 & $\begin{array}{l}1 \text { yr., F, } \\
\text { BMD }\end{array}$ & BFX & 5 & $42.6(10.8)$ & $13.4(21.8)$ & $24.0(27.7)$ & pTPO $25^{\circ}$ & $\begin{array}{l}\text { Luxoid } \\
\text { hip }\end{array}$ & $\begin{array}{l}\text { Head } \\
\text { exchange, } \\
\text { IFS }\end{array}$ & $\begin{array}{l}\text { Superficial } \\
\text { infection, } \\
\text { ventral } \\
\text { luxation }\end{array}$ & $\begin{array}{l}\text { Poor, } \\
\text { euthanasia }\end{array}$ \\
\hline 16 & $\begin{array}{l}\text { 5yr, M, } \\
\text { BMD }\end{array}$ & BFX & 31 & $54.9(30.9)$ & $14.3(24.0)$ & $29.6(28.0)$ & pTPO $25^{\circ}$ & High ALO & $\begin{array}{l}\text { Head } \\
\text { exchange, } \\
\text { IFS }\end{array}$ & None & Excellent \\
\hline 17 & $\begin{array}{l}6 \text { yr., } \mathrm{M} \\
\text { Australian } \\
\text { Terrier } \\
\end{array}$ & CFX & 12 & $69.0(48.8)$ & NA (31.6) & $21.7(22.8)$ & $\mathrm{tDCP} \approx 40^{\circ}$ & $\begin{array}{l}\text { High } \\
\text { ALO, } \\
\text { luxoid hip }\end{array}$ & IFS & None & Excellent \\
\hline 18 & $\begin{array}{l}6.5 \text { yr., M, } \\
\text { Australian } \\
\text { Terrier }\end{array}$ & CFX & 39 & 71.7 (26.6) & $29.7(34.2)$ & NA & $\mathrm{tDCP}$ & $\begin{array}{l}\text { High } \\
\text { ALO, } \\
\text { luxoid hip }\end{array}$ & IFS & None & Excellent \\
\hline
\end{tabular}




\section{University Library}

\section{- M M I N E R VA A gateway to Melbourne's research publications}

Minerva Access is the Institutional Repository of The University of Melbourne

Author/s:

Monotti, IC;Ryan, SD;Preston, CA

Title:

Management of total hip replacement luxation with triple pelvic osteotomy

Date:

2018-11-01

Citation:

Monotti, I. C., Ryan, S. D. \& Preston, C. A. (2018). Management of total hip replacement luxation with triple pelvic osteotomy. VETERINARY SURGERY, 47 (8), pp.993-1001. https:// doi.org/10.1111/vsu.12949.

Persistent Link:

http://hdl.handle.net/11343/284545 